\title{
Feasibility of In Situ Controlled Heat Treatment (ISHT) of Inconel 718 During Electron Beam Melting Additive Manufacturing
}

\author{
W.J. Sames ${ }^{1,2}$, K.A. Unocic, ${ }^{4}$ G.W. Helmreich ${ }^{3}$, M.M. Kirka ${ }^{2,4}$, F. Medina ${ }^{5}$, R.R. Dehoff ${ }^{2,4}$, \\ and S.S. Babu ${ }^{2,3}$ \\ ${ }^{1}$ Department of Nuclear Engineering, Texas A\&M University, College Station, TX; ${ }^{2}$ \\ Manufacturing Demonstration Facility, Oak Ridge National Laboratory, Knoxville, TN; ${ }^{3}$ \\ Department of Mechanical, Aerospace, and Biomedical Engineering, University of \\ Tennessee, Knoxville, TN; ${ }^{4}$ Materials Science and Technology Division, Oak Ridge \\ National Laboratory, Oak Ridge, TN; ${ }^{5}$ Arcam AB, Sweden \\ Keywords: Additive Manufacturing, Electron Beam Melting, Post-processing, Ni-base \\ superalloy
}

\begin{abstract}
A novel technique was developed to control the microstructure evolution in Alloy 718 processed using Electron Beam Melting (EBM). In situ solution treatment and aging of Alloy 718 was performed by heating the top surface of the build after build completion scanning an electron beam to act as a planar heat source during the cool down process. Results demonstrate that the measured hardness $(478 \pm 7 \mathrm{HV})$ of the material processed using in situ heat treatment similar to that of peak-aged Inconel 718. Large solidification grains and cracks formed, which are identified as the likely mechanism leading to failure of tensile tests of the in situ heat treatment material under loading. Despite poor tensile performance, the technique proposed was shown to successively age Alloy 718 (increase precipitate size and hardness) without removing the sample from the process chamber, which can reduce the number of process steps in producing a part. Tighter controls on processing temperature during layer melting to lower process temperature and selective heating during in situ heat treatment to reduce over-sintering are proposed as methods for improving the process.
\end{abstract}

Notice of Copyright This manuscript has been authored by UT-Battelle, LLC under Contract No. DEAC05-00OR22725 with the U.S. Department of Energy. The United States Government retains and the publisher, by accepting the article for publication, acknowledges that the United States Government retains a non-exclusive, paid-up, irrevocable, world-wide license to publish or reproduce the published form of this manuscript, or allow others to do so, for United States Government purposes. The Department of Energy will provide public access to these results of federally sponsored research in accordance with the DOE Public Access Plan (http://energy.gov/downloads/doe-public-access-plan). 


\section{Introduction}

In metal AM, standard practice is to use some combination of thermal post-processing steps to improve mechanical properties before deployment in service: stress relief, solution treatment, Hot-Isostatic Pressing (HIP), and aging. [1] These steps are designed to relieve residual stress, reset precipitate phase structure, reduce process-induced porosity, and produce the desired precipitate phase structure, respectively. Due to relatively low levels of residual stress [2] and porosity in EBM parts, it may be possible to eliminate the need for stress relief and HIP for EBM material. Nevertheless, post-processing methods including solution treatment and aging (STA) are required to achieve the desired level of hardness (and add the need for extra equipment and processing steps). This paper explores whether STA may be performed in situ, producing parts with the desired microstructure directly from the machine, without the need for any post process heat treatments.

\section{Background}

The principle strengthening phase of Alloy 718 is the $\gamma^{\prime \prime}$ phase, which is primarily associated with coherency hardening of $\gamma$ matrix. [3] Previous transmission electron microscopy (TEM) analysis indicated that peak aging of Alloy 718 sheet (i.e., after an aging at $720^{\circ} \mathrm{C}$ for 8 hours, $621^{\circ} \mathrm{C}$ for 8 hours) after solution treatment led to a $17 \pm 3 \%$ volume fraction of precipitates $\left(\gamma^{\prime \prime}+\gamma^{\prime}\right)$. [4, 5] It is also clear that this measured percentage of precipitates by TEM can be highly variable due to small sample size relative to entire product, if the underlying microstructure is heterogeneous. Such heterogeneous microstructures are usually found in cast and weld samples. The key question in our research is to evaluate the similarity of the microstructure in samples produced by electron beam melting (EBM). The details of EBM machine operation and processing have been reviewed in detail elsewhere [6], EBM of Inconel alloys using standards processing strategies has been previously characterized [7-12], and comparisons of EBM to other metal AM processes have been previously made. [13] Typical microstructure of EBM Alloy 718 has columnar solidification $(\gamma)$ grains, oriented with the <001> direction aligned in the build direction. The microstructure of EBM Alloy 718 has been noted to vary with location within the build volume, cool down, and thermal history. [14] The process hold temperature as a part builds may cause direct precipitation of $\delta$-phase needles in some cases but is not observed in all samples, due to process parameter variations. [6]

Recently, microstructure evolutions during post processing of AM samples have been studied extensively. For example, research in powder bed Selective Laser Melting (SLM) of Alloy 718 [15] has shown that heterogeneous recrystallization can occur during annealing $\left(1160^{\circ} \mathrm{C}\right.$ for $\left.4 \mathrm{hr}\right)$. There is evidence that recrystallization in SLM occurs due to high levels of residual stress. [16] In contrast, in post-process heat treatment of EBM samples it has been noted that more homogenous grain growth occurred in Inconel 625 [10] than in SLM Alloy 718, though the mechanisms for grain growth or recrystallization during post-processing of EBM material have not been thoroughly explored. 
Control of solidification grain morphology and size has been understood for many years in the welding literature based on spatial variation of thermal gradient $(\mathrm{G})$ and liquid-solid interface velocity (R) within the melt pool. [17] The use of $\mathrm{G}$ versus $\mathrm{R}$ curves to predict microstructure in AM has been tried [18], but it has speculated that the mixed mode (equiaxed and columnar) is not observed due to continued columnar growth once it has been established during early stages. Many other papers have addressed the benefits of controlled grain structure [19,20], but only recently has demonstration of this control has been achieved in bulk control of direct energy deposition (DED) grain structure [21] and bulk [22] and local [23] control of EBM grain structure. Beam modulation in wire-fed, electron beam DED has also shown that beam modulation (rapid variance of the beam power) can be used to produce finer grain structure. [24] This alternative method causes a dynamic melt pool due to a rapidly changing heat flux. A compelling demonstration of on-demand local control of grain orientation was achieved using EBM of Alloy 718. This is demonstrated by embedding the letters D-O-E (stands for the sponsor of the research, the "Department of Energy") through misoriented grains within a highly <001> oriented $\gamma$ matrix. [23]

Microstructure control during AM is more complex, as it is influenced by both solid-state phase transformation and solidification characteristics (i.e. segregation). For example, during Selective Laser Melting (SLM) of Ti-6Al-4V, influencing the solidification rate through varying the scanning speed was observed to control precipitation of $\mathrm{Ti}_{3} \mathrm{Al}$ [25]. The segregation of aluminum during rapid solidification leads to periodic fluctuations of aluminum content, which is identified as a driving force for $\mathrm{Ti}_{3} \mathrm{Al}$ precipitation. While this precipitation may not directly occur during primary solidification, the non-equilibrium phase formations can occur during short time scales associated with remelting and solidification during subsequent beam passes. These remelting and solidification may occur within a few seconds to minutes in SLM, depending upon the process parameters and scanning conditions. Other work on low-purity copper notes the possibility of microstructure control of $\mathrm{Cu}_{2} \mathrm{O}$, but active microstructure control was not demonstrated. [26] Both examples of microstructure control still rely on solidification control (i.e. control of the beam speed, beam power, or scan strategy). Although useful, there is inherent limitation of process parameter variations within AM for a given geometry; this may not allow for optimization of both solidification and solid-state phase transformation, potentially forcing the optimization of one characteristic at the expense of the other.

An interesting approach to control microstructure forces solid-state phase transformations in (n$1)^{\text {th }}$ layer using the heat transfer from nth layer. Such effects were rationalized in DED [27] and EBM [14] processing of Inconel 718 samples. This leads to an interesting concept of in situ aging of material during AM. In DED, the onset of precipitation occurs by hundreds thermal gyrations within the precipitation temperature range. In contrast, during EBM, the precipitation occurs by slow cooling through the precipitation temperature range. Until these two papers, in situ aging of material have been considered a side effect of processing conditions, rather than a controllable feature. 


\section{Proof of Principle}

Mechanical testing on EBM processed Alloy 718 has demonstrated the effects of cooling rates on as-fabricated tensile properties. [9, 14] An increase in hardening (higher UTS, lower elongation) was observed for the use of slow cooling when compared to fast cooling; the mechanical properties for the fast cooled and slow cooled samples were measured to be: UTS of $942 \pm 61 \mathrm{MPa}$ and $1108 \pm 50 \mathrm{MPa}$, YS $(0.2 \%)$ of $590 \pm 40 \mathrm{MPa}$ and $869 \pm 32 \mathrm{MPa}$, and elongation of $34 \pm 2.6 \%$ and $22 \pm 1.8 \%$, respectively. This difference was ascribed to age hardening due to the difference in time at temperature. These results motivated the investigation of in situ heat treatment of EBM fabricated Alloy 718 to directly control as-fabricated precipitate fractions using a controlled cool down to room temperature.

The cool down rate following build completion in EBM was controlled by modifying build chamber atmosphere, using either vacuum (slow cooled: 0.07 to $0.08{ }^{\circ} \mathrm{C} / \mathrm{s}$ ) or helium injection (fast cooled: 0.1 to 0.2 ${ }^{\circ} \mathrm{C} / \mathrm{s}$ ). These values of cooling rate assume a linear rate between the process temperature and $600^{\circ} \mathrm{C}$. It may be assumed that the material is in solid solution; a $1000^{\circ} \mathrm{C}$ process hold temperature may dissolve or prevent formation of most phases, except for carbides. By assuming linear cooling conditions, a predicted continuous cooling

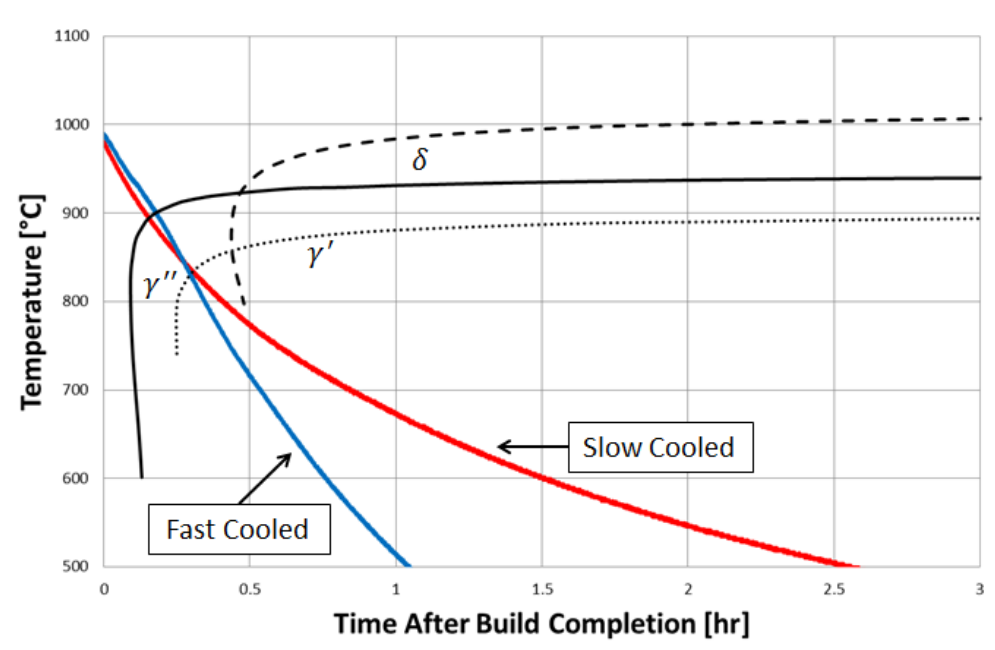

Figure 1: Build cooling curves measured at the under side of the base plate compared against Alloy 718 continuous cooling transformation curves calculated by JMatPro.

transformation (CCT) diagram may be used to evaluate possible phase formation (see Figure 1). The CCT diagram shows that the fast and slow cooled pathways both pass through the $\gamma^{\prime \prime}$ precipitation region are essentially the same. Cool down rates only diverge below $800^{\circ} \mathrm{C}$; it takes another $\sim 45$ minutes for the slow cooled to reach $600^{\circ} \mathrm{C}$ than for the fast cooled. Based on these observations, the resulting hardness difference is attributed to enhanced coarsening of the precipitates that originally formed above $750^{\circ} \mathrm{C}$. Due to the limited fidelity of the cooling rate variations, a third concept that combines the cool down technique with in situ heat treatment (ISHT) is proposed. If proven feasible, ISHT will provide an innovative control of solidification and solid-state transformation during EBM process through a priori design of processing parameters. 


\section{Experimental Methods:}

\section{Description of In Situ Heat Treatment}

An Arcam A2 EBM machine running EBM Control software version 4.1 was used to produce the ISHT sample. The samples for the ISHT were produced with plasma atomized powder provided by Advnaced Powder and Coatings (Quebec, Canada). The melt layer thickness was maintained at $75 \mu \mathrm{m}$. The slow cooled and fast cooled cases used for comparison were built with previously reported machine parameters of $50 \mu \mathrm{m}$ layers, gas atomized powder, and EBM Control version 3.2 software. The ISHT was accomplished by engaging planar heating over the build substrate using the "Start Plate Heating" function; after the melting process is completed, the cool down process was stopped and the heating process was restarted. The restart of processing prompts the user to engage heating. This option is originally intended to reheat the surface temperature

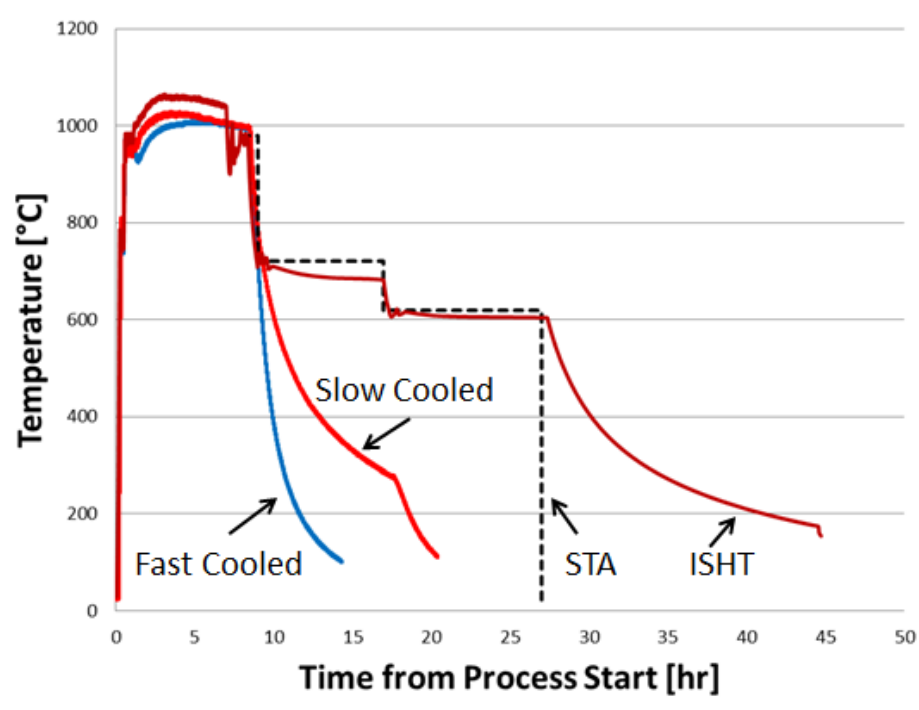

Figure 2: Thermal histories as measured from start plate thermocouple for various cool down techniques. The standard HT is graphed for comparison to the ISHT.

following process

changes or machine stops. This heating was engaged and used as the heat source for the ISHT. The heating parameters are defined under the Start Plate Theme, and use a diffuse beam (focus offset of $80 \mathrm{~mA}$ ), line offsets, and rotation in an attempt to achieve uniform, planar heating. This heating function must specify either a square of circular area. The software offers new functions that have the ability to heat over the area of the previous part layer, instead of the powder area. The square area was used to heat over the entire part surface and enclosed powder bed area. The beam scans a single line at a time, skipping lines (usually 20 lines) to prevent the buildup of heat locally; the beam iterates scanning every 20 lines, until the entire area has been passed over. This is done for a number of iterations, and then the process is rotated 90 degrees to prevent "striping". Striping creates "stripes" of sintered material in comparison to the rest of a surface owing to the repeated pass of the beam over the same line.

Table 1. Process current used to achieve in situ heat treatment. 


\begin{tabular}{|l|c|c|c|}
\hline Solution Treatment (ST) & 980 & 1 & $30-31$ \\
\hline Aging (precipitation) & 720 & 8 & $11-12$ \\
\hline Aging (coarsening) & 620 & 10 & $8-11$ \\
\hline
\end{tabular}

The beam current is a critical parameter for this heating step. The beam will use this current value to heat to a preset temperature. If this temperature is not reached in a certain time, the process will "time out" and stop. The ISHT attempted to match the conventional, or "standard", post-processing steps as detailed in Table 1 and shown in Figure 2 [28]. The currents reported for different process steps include the currents used to heat the substrate thermocouple to the desired temperature range. Isothermal hold temperatures were achieved by increasing the heating timeout (normally 1 to 4 hours) to an arbitrarily large number (>20 hours) while fixing the current to an underpowered level (values given in Table 1). The heating timeout is a value set to limit the amount of time that the machine tries to heat before a build fails. By increasing this value to $>20$ hours, the entire in situ processing step can be run without the machine turning off and failing the build. The feasibility of making builds using this approach will be discussed below.

\section{Material characterization}

Samples for tensile testing consisted of cylindrical round bars with a gauge diameter of $2.54 \mathrm{~mm}$ and gage length of $25.4 \mathrm{~mm}$. Tensile testing was conducted on a custom built servo-hydraulic load frame. Hardenss testing was conducted on a LECO LM Vickers Hardness indenter. Microstructure characterization was performed using a Hitachi 4800-S scanning electron microscope (SEM) after the samples had been metallographically prepared and etched via submersion using a mixture of HCL, acetic acid, and HNO3 in a 1:1:1 ratio. To develop grain orientation maps, a JEOL 6500 SEM equipped with an electron backscatter diffraction (EBSD) detector was used.

TEM foils were prepared from samples that underwent slow cooling and ISHT. TEM samples were cut from a bulk samples perpendicular to the build direction, and mechanically ground to a thickness of $\sim 100 \mu \mathrm{m}$ prior to being punched into 3-mm disks. The pre-thinned 3-mm disks were jet polished in an electrolyte containing $60 \%$ methanol, $35 \%$ 2-n butoxyethanol (butyl cellusolve), and $5 \% \mathrm{HClO}_{4}$ (perchloric acid) at $-40{ }^{\circ} \mathrm{C} / 15 \mathrm{~V}$. The slow cooled sample underwent an additional 3.5 hours of ion milling because it was not electron transparent. Some surface damage could be observed on the surface due to the additional ion milling step. Scanningtransmission electron microscope (STEM) (Philips model CM200) equipped with a Schottky field emission gun (FEG) and x-ray energy dispersive spectrometer (EDS) and operated at 200kV, a JEOL 2200FS-AC STEM $200 \mathrm{kV}$ probe-corrected microscope (using CEOS $\mathrm{C}_{\mathrm{s}^{-}}$ Corrector) equipped with a Bruker XFlash 6|30 silicon drift detector, 


\section{Results and Discussions}

\section{Feasibility of Builds with ISHT}

In this process we used electron beam to heat continuously and the powder bed to reach an equilibrium temperature dependent on the fixed current. Cooling between process steps was achieved by manually stopping the electron beam and vacuum cooling until the lower temperature range was reached. It was assumed that the temperature measured from the substrate was representative of the temperature throughout the powder bed. The control case held close to $1000^{\circ} \mathrm{C}$ for the entirety of processing (until the build was complete), while the ISHT case peaked at $1065^{\circ} \mathrm{C}$. This hold temperature was far higher than other typical Alloy 718 builds $\left(\sim 1000^{\circ} \mathrm{C}\right)$. This abnormality in processing can be attributed to variation in the "Mean Power" of "Average Current" parameter. This parameter is used to calculate an energy balance based on process time, where a post-heating step is used to heat the build after melting is complete (but before distributing a new layer). The ISHT value was set at $21 \mathrm{~mA}$, whereas the control case was adjusted to $18 \mathrm{~mA}$. This variation was unintentional, and was the result of ongoing parameter optimization efforts (the lower value of $18 \mathrm{~mA}$ was not saved into the process theme). The higher value of Average Current means that post-heating was engaged for a longer period of time during the melt processing of the ISHT case.

a)

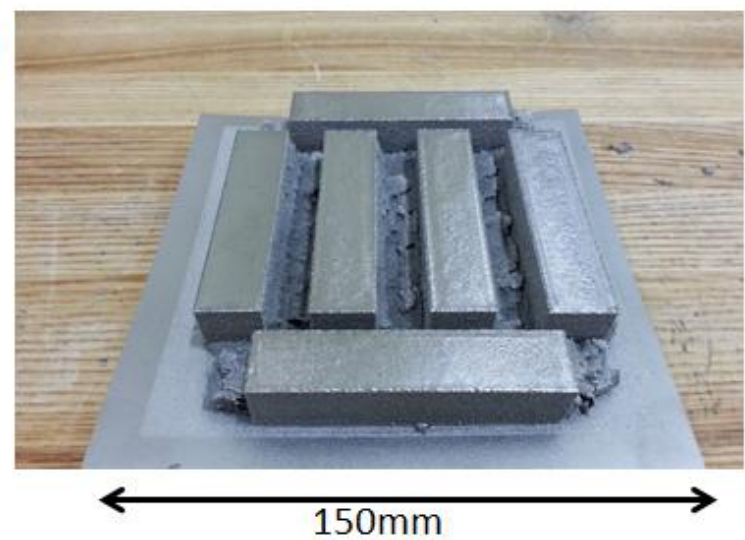

b)

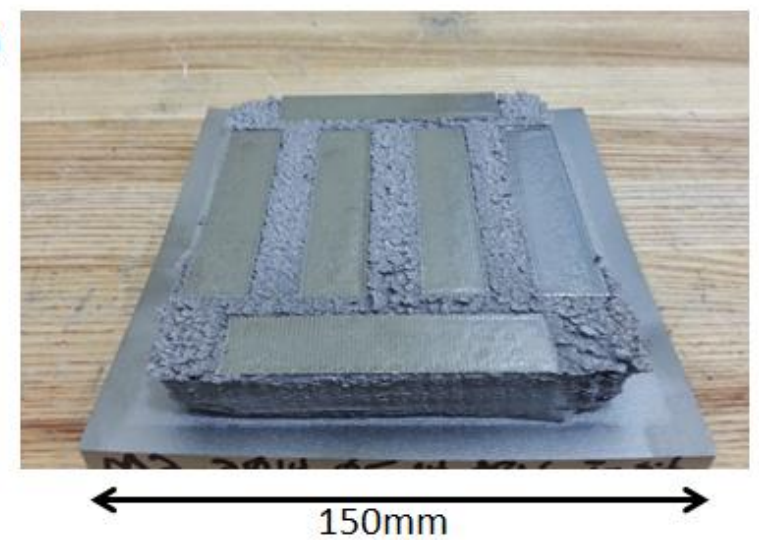

Figure 3. Builds showing (a) a control build and (b) the result of the in situ heat treatment. Due to processing conditions, significant over-sintering of powder occurred during in situ processing.

The resulting parts from a control build and the ISHT are shown in Figure 3. During the ISHT build, the powder surrounding the parts was largely over-sintered and not recoverable. This can be attributed to the locally high energy density of the beam used for the ISHT process. While, over sintering of the powder represents a significant limitation to the ISHT, future developments of the EBM process controls and process parameter development could potentially mitigate the problem. While, complex geometries with internal cavities present additionally challenges in the removal of sintered powder due to clear lack of sight of the material, ultrasonic vibration techniques could be used to break down the powder and remove from the structure. 


\section{Solidification Grain Structure ISHT Builds}

Although our primary focus is only the modification of solid-state precipitation during cool down process, it is important to evaluate whether our changes in EBM conditions have inadvertently lead to large changes in the macrostructure. Significant cracks were present in the ISHT samples, aligned parallel to columnar grains and the build direction (Z-axis). SEM shows cracks in the ISHT sample extend the length of the observation distance $(>850 \mu \mathrm{m})$ (Figure 4). The cracks, though mostly aligned, do not appear to adhere to grain boundaries. Contrast difference in the SEM image can be related to grain orientation, and the cracks can be seen within the interior of some regions of the same contrast. Such cracking was not observed in the standard samples. In order to rationalize the nature of these cracks, the regions where EBSD was performed showed no cracking in un-etched samples along grain boundaries (high or low angles).

The ISHT resulted in large solidification grains and cracking parallel to the build direction (along the z-axis). EBSD shows that the columnar grains extend at least the length $(>700 \mu \mathrm{m})$ of the observation distance, (Figure 5) which is much larger than the grain size seen in a control sample [Ref]. Though the grains are large, the grain orientation and columnar structure remains intact (no growth of misoriented or recrystallized grains was observed). Small clusters of misoriented grains are seen in both the control and ISHT samples. Of particular note is the absence of any annealing twins in the ISHT study; annealing twins have been observed in large grain growth cases for EBM Inconel 625 [10] and EBM Inconel 718 [6, 8], but those cases also experienced disruption of the columnar grain structure.
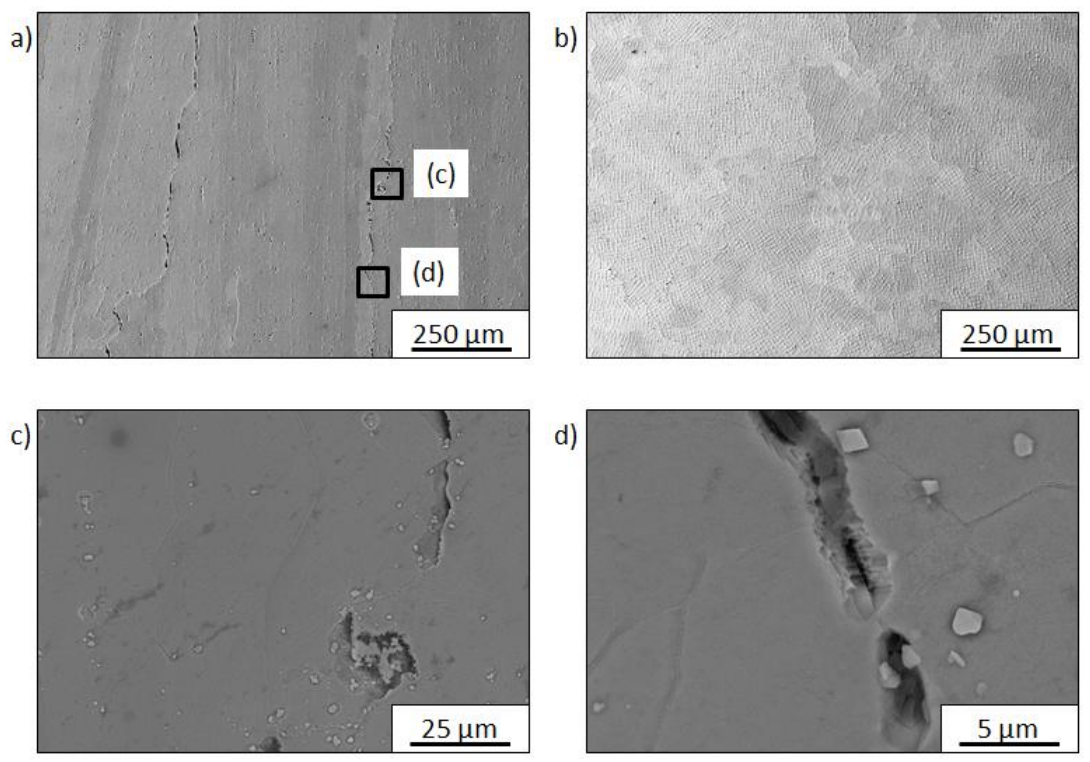

Figure 4. Secondary electron SEM images of etched in situ heat treatment sample along (a) XZ-plane showing cracks extending the length of observation $(>850 \mu \mathrm{m})$, (b) XY-plane showing repetitive carbide precipitate structure aligned to interdendritic regions, (c-d) higher resolutions of observed crack. 
a)

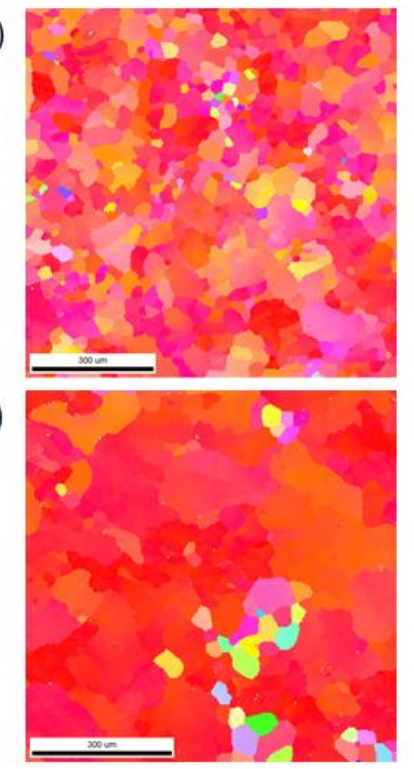

b)

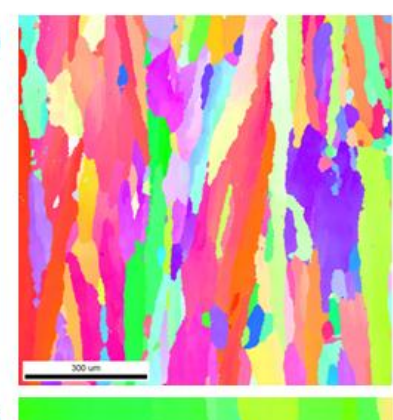

d)

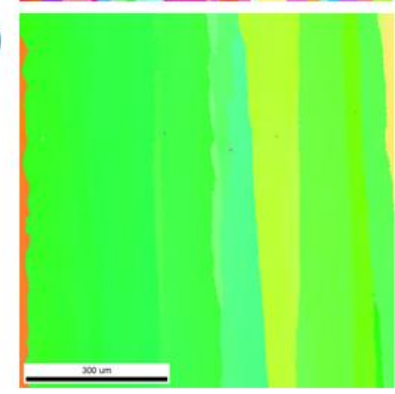

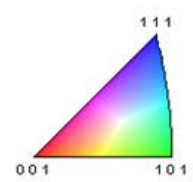

Figure 5. Inverse pole figure maps created from EBSD data showing grain structure for a control case in the (a) XY plane and (b) XZ plane, and for in situ heat treatment in the (c) $X Y$ plane and (d) $X Z$ plane. Images of the $X Y$ plane are taken near the top $(Z \sim 20 \mathrm{~mm})$ of the sample, whereas $X Z$ images were taken near the center $(Z \sim 10 \mathrm{~mm})$ of the sample.

The large grain size was likely a result of an elevated processing hold temperature (peak of $1065^{\circ} \mathrm{C}$ ), though the mechanism for producing the large grains must be considered. Two pathways for the formation of large grains must be considered: (1) grain growth and (2) formation during solidification. The $\delta$-solvus for Alloy 718 is $\sim 1010^{\circ} \mathrm{C}$ [33], and grain boundary $\delta$-phase is typically used to control $\gamma$-matrix grain growth. [34] Above $\sim 1040^{\circ} \mathrm{C}$, discontinuous grain growth is typical in wrought Alloy 718 and continuous grain growth has been observed in spray-formed Alloy 718. [35] Thus, the ISHT build temperature was high enough above the $\delta$-solvus that grain growth could have occurred in previous layers during ongoing layer melting. In addition to the high process temperature, a one-hour solution treatment $\left(980^{\circ} \mathrm{C}\right)$ hold was engaged directly following the melting process. This step may have contributed to growth, if fluctuations during manual control of process heating led to surface temperatures in excess of the $\delta$-solvus (if no GB $\delta$-phase was present). After this step, GB $\delta$ phase is predicted to form based on standard time-temperature-transformation kinetics. [28] The presence of GB $\delta$-phase would make grain growth during aging unlikely.

Strain-age cracking (SAC) is typically associated with carbides or Laves phase near GBs, in regions of segregation. [36] While cracks were not observed exclusively at GBs in the ISHT sample, constitutional segregation during solidification is also known to occur within grains in Alloy 718 (i.e., related to interdendritic regions within a single grain). In EBM of Alloy 718, columnar architectures of carbides are present in the bulk structure, which are associated with these intragranular, interdendritic regions. The cracks observed have some serrated or "jagged" edges (Figure 4(c) and Figure 4(d)), which have been noted in previous work [37] in SLM of 
CM247LC (a nickel-based superalloy) to be related to cracking during a semi-liquid, solidification state. This form of cracking in the study by Carter et al. [37] was shown to be associated with higher energy melting (which was also the case for the ISHT melting sample, which operated at higher temperature). However, cracks in the ISHT sample exhibit greater tendency to align parallel the build direction than the previous results showing no preference for crack orientation. [37] Carter et al suggest that alignment in the build direction can be associated to GB cracking near carbides (though crack boundaries in the ISHT case were more "clean"). Irrespective of solidification grain structure changes, the presence of cracks will have large influence on the tensile properties.

\section{Precipitation Characteristics}

The resulting microstructures of the fast cooled, slow cooled, and ISHT cases show variation in precipitate size and morphology that is characteristic of the age hardening of Alloy 718. SEM analysis of characteristic precipitate phases of the matrix (Figure 6) shows that a decreasing cooling rate results in a transition from small, spherical particles (Figure 4a)) to larger, slightly elongated disks (Figure 6 (b)). This elongation and increase in precipitate size is consistent with the strengthening effect seen in tensile properties. The ISHT exhibited even more coarsening of precipitates as seen in Figure 6(c). Image analysis was performed on SEM images of the precipitates, assuming that the precipitates being measured were $\gamma^{\prime \prime}$ with disk morphology. ImageJ was used to set the scale and manual measurements were taken across the long dimension (assumed to be diameter) and short dimension (assumed to be thickness) of representative particles. The fast cooled case was not analyzed due to the ambiguity of dimensions (all particles appear spherical). The slow cooled case was found to have a diameter of $19 \pm 5 \mathrm{~nm}$ and a thickness of $9 \pm 2 \mathrm{~nm}$. The ISHT case had a diameter of $39 \pm 13 \mathrm{~nm}$ and a thickness of $13 \pm 3 \mathrm{~nm}$. The diameter of $\gamma^{\prime \prime}$ disks is expected to grow preferentially compared to the thickness, [29] as is observed here. For conventional aging of powder metallurgy material, $\gamma^{\prime \prime}$ disks are expected to be 25 to $35 \mathrm{~nm}$ in diameter and 7 to $12 \mathrm{~nm}$ thick. [30] The ranges of precipitate sizes for both cases overlap the conventional range. 
Notably, the ISHT did not form large quantities of the intragranular, needle $\delta$ phase that has been observed in previous work on EBM Alloy 718. [7, 8] This may be attributable to the fact that the long hold for the ISHT was not in the temperature range for direct precipitation of $\delta$-phase from the matrix; the hold temperature for the ISHT was within the range for $\gamma^{\prime \prime} / \gamma^{\prime}$ formation and coarsening. Formation of $\delta$-phase in this temperature region is mostly limited to cellular formation on $\mathrm{GBs}\left(<700^{\circ} \mathrm{C}\right)$ or transformation of $\gamma^{\prime \prime} \rightarrow \delta$ due to overaging $\left(750-800^{\circ} \mathrm{C}\right)$. [31]

The above precipitate characteristics were further verified using transmission electron microscopy (TEM) verified the presence of both $\gamma^{\prime}$ and $\gamma^{\prime \prime}$ strengthening phases and confirmed the increase in $\gamma^{\prime \prime}$ size achieved by the ISHT. In both the slow cooled and ISHT samples, uniformly distributed $\gamma^{\prime \prime}$ and $\gamma^{\prime}$ were observed throughout the grain interiors (Figure 7). The size increase of $\gamma$ " in the ISHT case observed in SEM is confirmed here through TEM. This proves that the ISHT was able to achieve the desired aging effect on the precipitate microstructure. a)

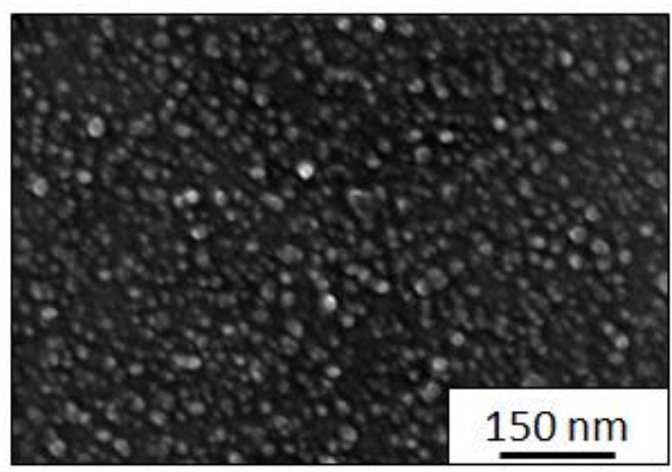

b)

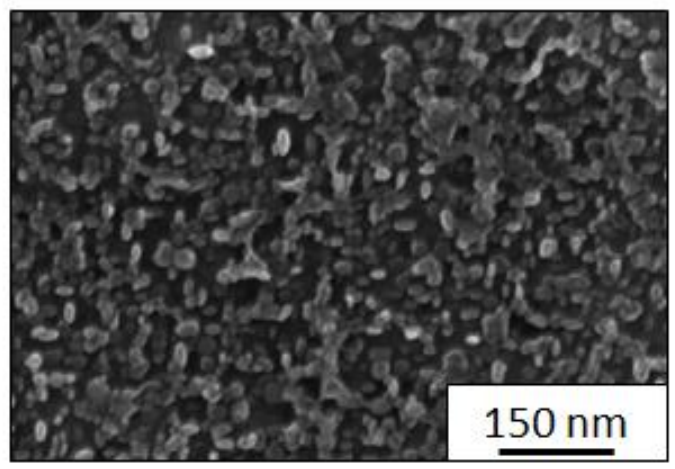

c)

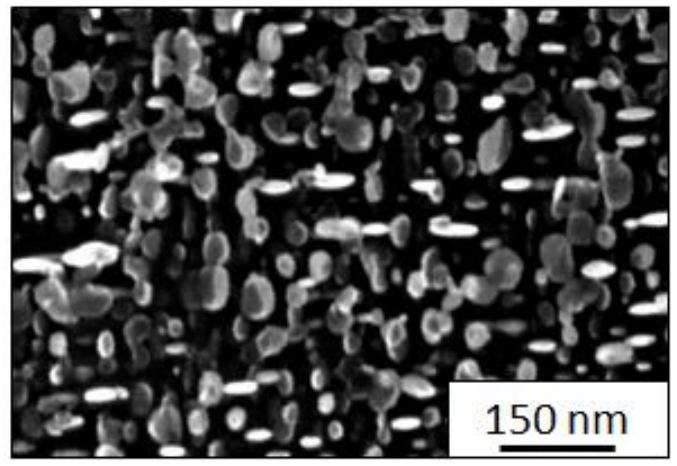

Figure 6: SEM of precipitates in the matrix for (a) fast cooled, (b) slow cooled, and (c) in situ heat treatment. 
a)

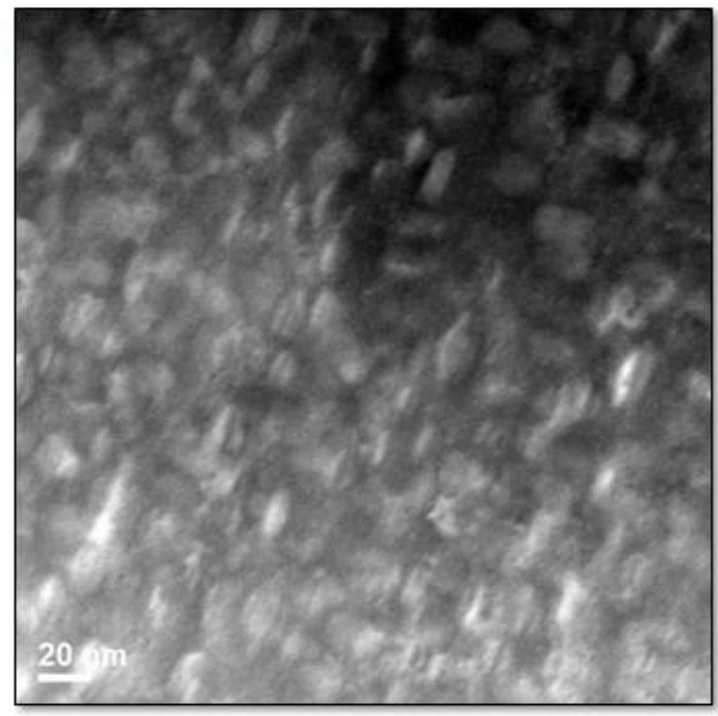

b)

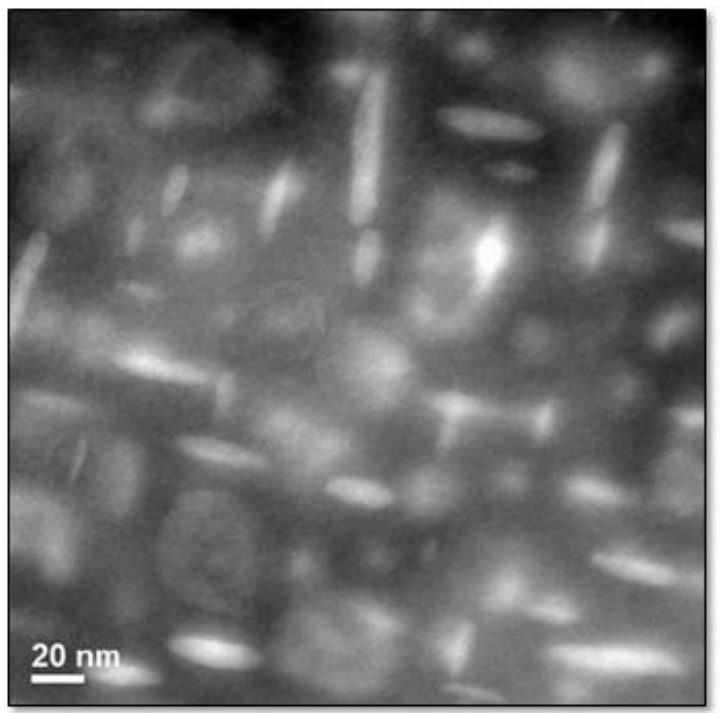

Figure 7. HAADF-STEM showing an increase in $\gamma^{\prime \prime}$ size between (a) the slow cooled sample and (b) the in situ heat treatment (ISHT) sample.

All TEM results presented for both samples were examined in the XY plane, perpendicular to the build direction. It was noted that small tilts $\left(\sim 5^{\circ}\right)$ were required during TEM to align the ISHT sample to the [001] zone indicative of grains growth almost along [001] direction during EBM process. Much larger tilts $\left(\sim 30^{\circ}\right)$ were required to align the slow cooled sample to the [001] zone, which suggests that the growth direction of the material during EBM process was slightly misoriented from the [001] build direction. Carbides were also observed in the slow cooled microstructure (Figure 8$)$. The larger carbide $(>0.3 \mu \mathrm{m}$ diameter) shows the presence of both $\mathrm{Nb}$ and Ti. The smaller carbides $(<0.2 \mu$ m diameter) only show the presence of $\mathrm{Ti}$. ( $\mathrm{Fe}, \mathrm{Cr}, \mathrm{Ni}$ )enriched precipitates were also noted to be present along grain boundaries; however, no further characterization of these phases was carried out since this was not an objective of this characterization.

Electron diffraction characterization (see Fig. 9) was carried out to identify phases inside the $\gamma$ grain. Example of electron diffraction pattern oriented along [001] $\gamma$ zone axis is shown in Figure 9c. In addition to the $\gamma$ matrix reflections superlattice reflections of $\{100\}$ and $\{110\}$ corresponding to both $\gamma^{\prime}$ and $\gamma^{\prime \prime}$ are also observed, while the additional $\left\{\begin{array}{lll}1 & 1 / 2 & 0\end{array}\right\}$ reflections correspond only to $\gamma^{\prime \prime}$ particles [38] confirming that bulk matrix precipitates contain both type of particles $\gamma^{\prime}$ and $\gamma^{\prime \prime}$. EDS analysis further confirms that plate-like precipitates are $\gamma^{\prime \prime}$ precipitates containing $\mathrm{Ni}, \mathrm{Nb}$ and $\mathrm{Ti}$ with $\mathrm{D}_{22}$ structure [32], which is the main strengthening phase in the alloy. Though the bulk matrix phases were identified as $\gamma^{\prime \prime} / \gamma^{\prime}$, there are some matrix areas (Figure 9b) with additional phases (Figure 9c) that were not fully characterized but most likely they are $\delta$-phase with needle like shape. 

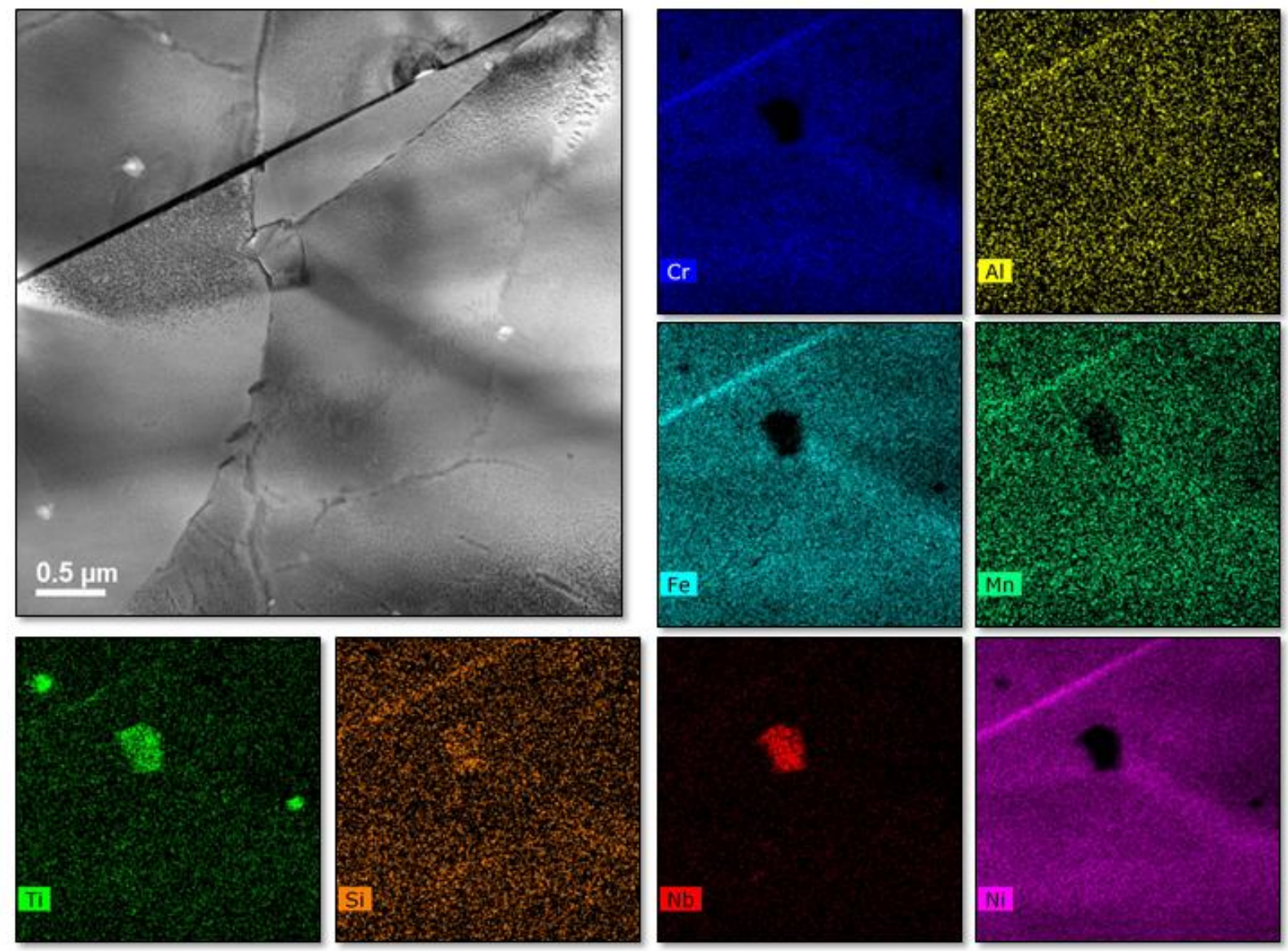

Figure 8. DF STEM image of slow cooled sample with EDS composition maps showing concentration of $\mathrm{Nb}, \mathrm{Ti}$ in carbides.

a)

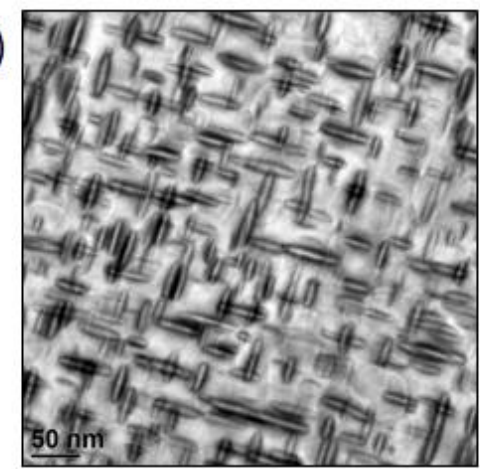

b)

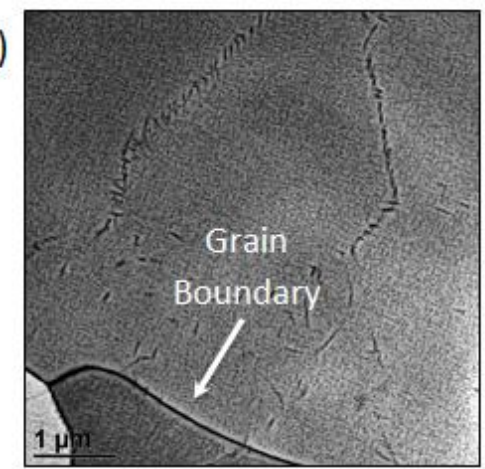

c)

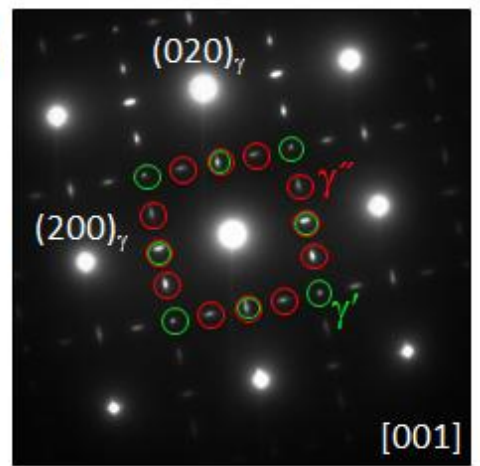

Figure 9. BF-STEM image of ISHT sample showing (a) $\gamma^{\prime \prime} / \gamma^{\prime}$ within $\gamma$ matrix, (b) low magnification BF-STEM image showing networks of phases from solidification, (c) electron diffraction pattern oriented along [001] $\gamma$ zone axis showing in addition to the $\gamma$ matrix reflections superlattice reflections of $\{100\}$ and $\{110\}$ corresponding to both $\gamma^{\prime}$ and $\gamma^{\prime \prime}$. The additional $\left\{\begin{array}{ll}1 / 2 & 0\end{array}\right\}$ reflections correspond only to $\gamma^{\prime \prime}$ particles confirming that bulk matrix precipitates contain both type of particles $\left(\gamma^{\prime \prime} / \gamma^{\prime}\right)$. 

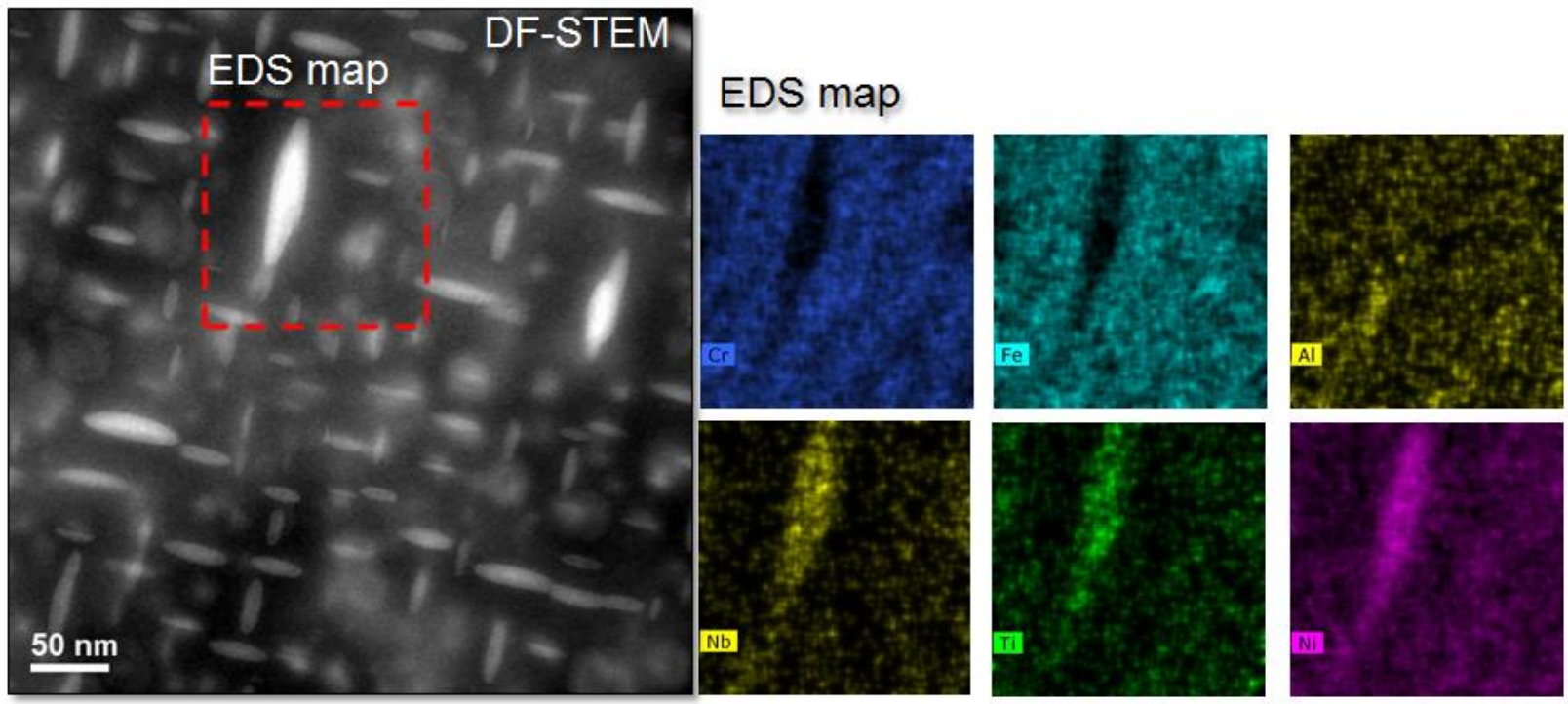

Figure 10. DF STEM image generated from the in situ heat treatment (ISHT) sample in conjunction with EDS maps showing example of composition of typical matrix phases.

These phases are seen in standard as-fabricated samples and persist in the ISHT sample. These phases are associated with solidification segregation, though the EBM process does do a certain amount of in situ homogenization as parts continue to build. [6] The $\gamma^{\prime \prime}\left(\mathrm{Ni}_{3} \mathrm{Nb}\right)$ phase is associated with aging or solid-phase transformation and was observed to be enriched in titanium in addition to niobium and nickel (Figure 10).

\section{Mechanical Properties}

With the above microstructural observations, the obvious question is whether we achieved improved strength with ISHT samples. This was first evaluated by measuring the hardness. Baselines for hardness comparisons to peak-aged (466 HV), un-aged (275 HV), and under-aged (350HV) material were taken from previous analysis of rolled bar by Slama et al. [39] The hardness values of the fast cooled, slow cooled, and ISHT were compared in the z-direction (Figure 11), and a summary of average hardness is given in Table 2.

Table 2. Vickers hardness values averaged across a full range of $\mathrm{X}$ - and Z-positions in each sample.

\begin{tabular}{|c|c|c|c|}
\hline Condition & $\begin{array}{c}\text { Average } \\
\text { Hardness [HV] }\end{array}$ & $\begin{array}{c}\text { Min } \\
\text { Hardness [HV] }\end{array}$ & $\begin{array}{c}\text { Max } \\
\text { Hardness [HV] }\end{array}$ \\
\hline Fast Cooled & $324 \pm 18$ & 282 & 368 \\
\hline Slow Cooled & $392 \pm 15$ & 355 & 424 \\
\hline In Situ Heat Treatment & $478 \pm 7$ & 462 & 493 \\
\hline
\end{tabular}

Hardness values were collected as an array and then sorted into X-and Z-values. The fast cooled had the lowest hardness (as expected), which is somewhere between un-aged and under-aged 
material. The slow cooled specimen had higher hardness values than the fast cooled material but lower hardness values than the in situ material. The slow cooled material had higher hardness than under-aged material but lower than peak aged. Interestingly, ISHT material had the highest hardness (478 HV), which was above peak aged material (466 HV). This confirms that the ISHT can be used to age material in situ, confirming our original hypothesis.

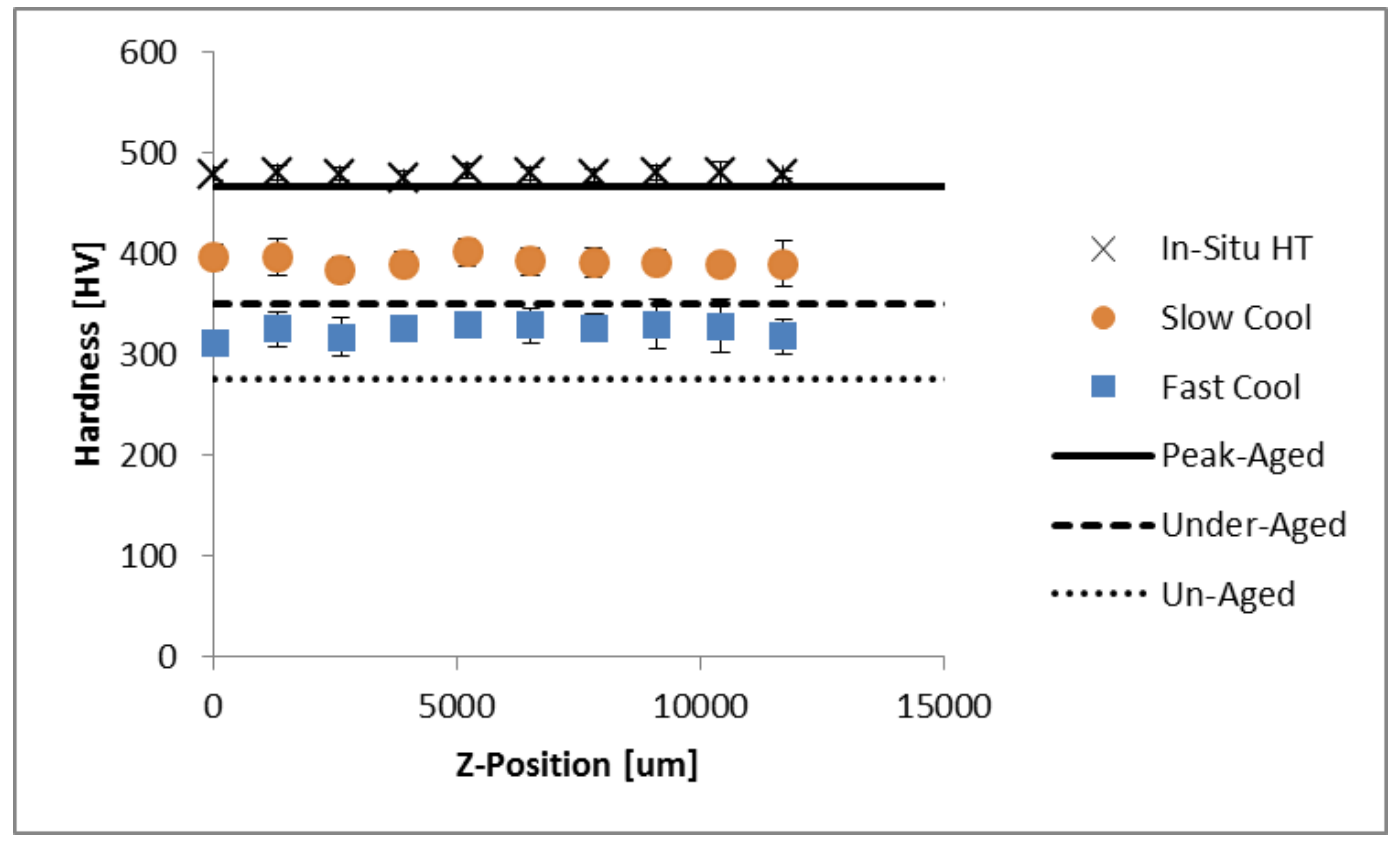

Figure 11: The hardness profile in the z-direction confirms uniform axial aging of material; the in situ condition is above the hardness of peak aged material

Since hardness was not observed to vary with Z-position (Figure 13), the assumption of an isothermal build volume appears to be valid for the relatively short ( $20 \mathrm{~mm}$ in height) geometry used herein. Additionally, no significant variation was noted with hardness in the X-direction. In situ temperature measurements of the top build surface during operation (using an IR camera or pyrometer) would be useful in the future, as this assumption may not hold for larger builds than the geometry used herein.

The next question is to confirm whether we were able to carry the improved strength even with the cracks observed in Fig. 4.Tensile testing was performed perpendicular to the build direction for the ISHT material; however, these tests failed during loading ( $<400 \mathrm{MPa}$ UTS, Figure 12Error! Reference source not found.). This was unexpected, as the control sample (YS of $568 \pm 5 \mathrm{MPa}$, UTS of $818 \pm 43 \mathrm{MPa}$, and elongation of $16.9 \pm 2.9 \%$ ) was on the same order of magnitude of previous studies [9] of EBM Alloy 718 (YS of 590-974MPa, UTS of 942 to $1186 \mathrm{MPa}$, and elongation of 5.4 to $34 \%$ ). The lower values of YS, UTS, and elongation seen in the control sample may be explained by process parameter variation compared to the previously quoted results for EBM Alloy 718. The poor tensile performance of the ISHT samples is concluded to be a result of the large, aligned cracks observed in the sample (see Fig. 4). By pulling the tensile tests perpendicular to the cracks, the samples failed at the locations and 
displayed columnar, striations along the length of the fracture surface. Further work is needed to better study crack formation to improve tensile results; this may be as simple as tighter processing controls to restrict the processing temperature during melting to $\sim 1000^{\circ} \mathrm{C}$.

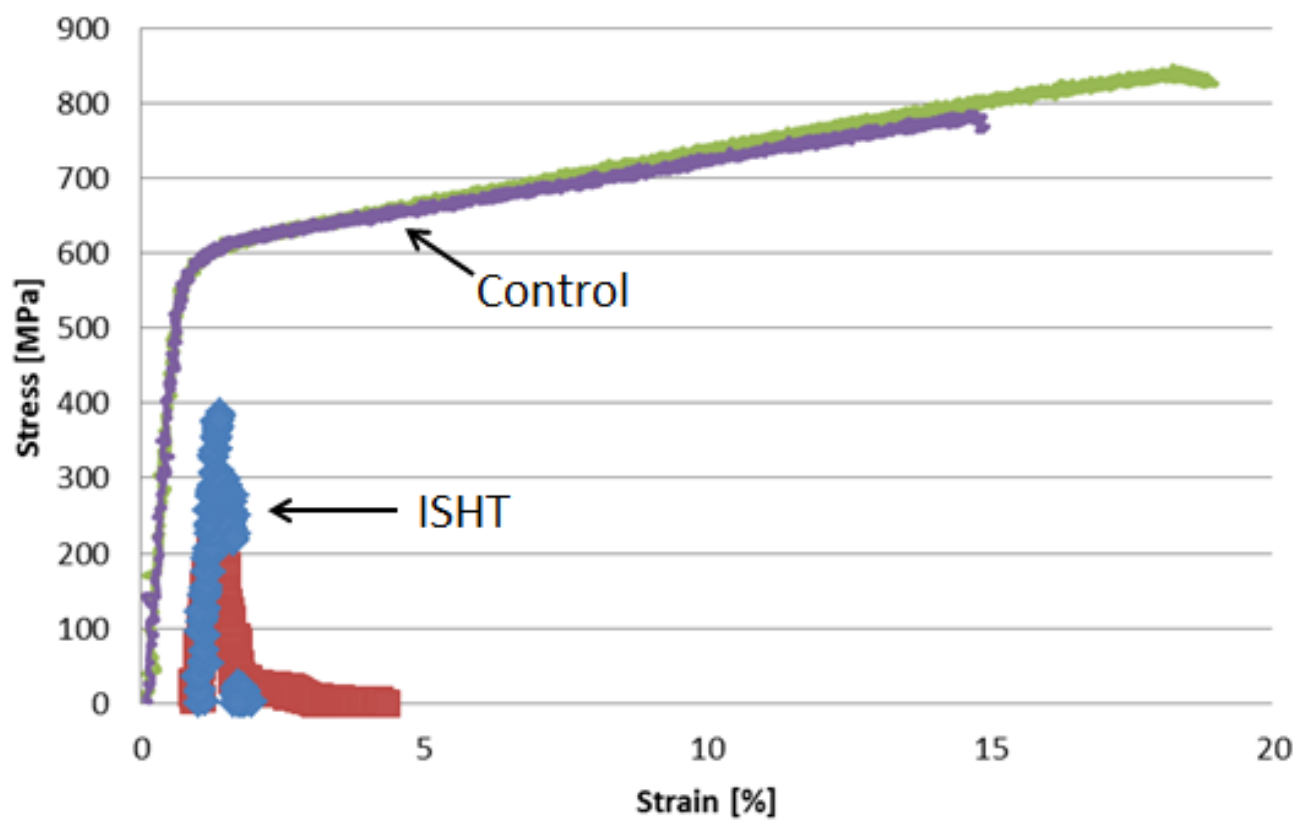

Figure 12. The tensile properties of the control case were comparable to previous results of EBM Alloy 718, but the ISHT samples failed under loading.

Based on earlier discussions, we correlate the cracking tendency to strain-age cracking or liquation near the carbide regions (see Figs. 4 and 8). Further work to pursue ISHT should focus on improved temperature control during melting (prior to ISHT) to better understand the limitations of this technique (as opposed to the limitations of processing at higher temperatures). Other work to understand grain growth in columnar, EBM material should be carried out to better rationalize the large, columnar grains identified in this work and the large, twinned, noncolumnar grains identified in other work in high temperature post-processing of EBM Alloy 718. It is important to note that the carbide formation is promoted due to the presence of carbon in IN818 alloys. The addition of carbon in these alloy systems were originally designed for traditional processing involving casting and thermos-mechanical processing with limited control of $\gamma$-grain texture. With possibility of spatial grain orientation that is possible with EBM, one may be able to modify the Alloy 718 composition to minimize the carbide formation, thereby reducing the cracking and is the focus of the ongoing research. 


\section{Conclusions}

The work presented herein represents a first attempt to achieve an a priori designed microstructure during additive manufacturing. A novel EBM additive manufacturing process with modified beam control was used to modify the cool down condition from the processing temperature. SEM and TEM confirmed that the modified EBM procedure lead to the precipitation of both $\gamma^{\prime \prime}$ and $\gamma^{\prime}$. The $\gamma^{\prime \prime}$ was disc shape, with a average diameter of $39 \pm 13 \mathrm{~nm}$ and a thickness of $13 \pm 3 \mathrm{~nm}$. The hardness of the ISHT material was comparable to peak aged wrought Alloy 718. However, this strengthening was not able to be carry over to improvement in tensile properties. Poor tensile performance of the in situ heat treatment technique were observed and related to a combination of unusually large grain size and cracking. An abnormally high processing temperature during melting was noted, which may have allowed caused hot tearing or liquation of interdendritic solidification phases to form the observed cracks.

\section{Acknowledgements}

Research sponsored by the U.S. Department of Energy, Office of Energy Efficiency and Renewable Energy, Advanced Manufacturing Office, under contract DE-AC05-00OR22725 with UT-Battelle, LLC. This research was also supported by fellowship funding received from the U.S. Department of Energy, Office of Nuclear Energy, Nuclear Energy University Programs. The United States Government retains and the publisher, by accepting the article for publication, acknowledges that the United States Government retains a non-exclusive, paid-up, irrevocable, world-wide license to publish or reproduce the published form of this manuscript, or allow others to do so, for United States Government purposes.

\section{References}

[1] ASTM-International, "Standard Specfication for Additive Manufacturing Nickel Alloy (UNS N07718) with Powder Bed Fusion," vol. F3055-14, ed. West Conshohocken, PA: ASTM International, 2014.

[2] L. M. Sochalski-Kolbus, E. A. Payzant, P. A. Cornwell, T. R. Watkins, S. S. Babu, R. R. Dehoff, et al., "Comparison of Residual Stresses in Inconel 718 Simple Parts Made by Electron Beam Melting and Direct Laser Metal Sintering," Metallurgical and Materials Transactions A, vol. 46, pp. 14191432, 2015/03/01 2015.

[3] J. M. Oblak, D. F. Paulonis, and D. S. Duvall, "Coherency strengthening in Ni base alloys hardened by DO22 $\gamma^{\prime}$ precipitates," Metallurgical Transactions, vol. 5, pp. 143-153, 1974/01/01 1974.

[4] R. Chandrasekar, "Swept frequency eddy current (SFEC) measurements of Inconel 718 as a function of microstructure and residual stress," Ph.D., lowa State University, 2013.

[5] R. Chandrasekar, C. C. H. Lo, A. M. Frishman, B. F. Larson, and N. Nakagawa, "Quantification of precipitates and their effects on the response of nickel-base superalloy to shot peening," AIP Conference Proceedings, vol. 1430, pp. 1437-1444, 2012.

[6] W. J. Sames, "Additive Manufacturing of Inconel 718 using Electron Beam Melting: Processing, Post-Processing, \& Mechanical Properties," Ph.D., Nuclear Engineering, Texas A\&M University, College Station, TX, 2015 (Internal Review). 
[7] A. Strondl, M. Palm, J. Gnauk, and G. Frommeyer, "Microstructure and mechanical properties of nickel based superalloy IN718 produced by rapid prototyping with electron beam melting (EBM)," Materials Science and Technology, vol. 27, pp. 876-883, 2011.

[8] K. A. Unocic, L. M. Kolbus, R. R. Dehoff, S. N. Dryepondt, and B. A. Pint, "High-Temperature Performance of N07718 Processed by Additive Manufacturing," in NACE Corrosion 2014, San Antonio, TX, 2014.

[9] W. J. Sames, F. Medina, W. H. Peter, S. S. Babu, and R. R. Dehoff, "Effect of Process Control and Powder Quality on Inconel 718 Produced Using Electron Beam Melting," in Superalloy 718 and Derivatives, Pittsburgh, PA, 2014.

[10] L. E. Murr, E. Martinez, S. M. Gaytan, D. A. Ramirez, B. I. Machado, P. W. Shindo, et al., "Microstructural Architecture, Microstructures, and Mechanical Properties for a Nickel-Base Superalloy Fabricated by Electron Beam Melting," Metallurgical and Materials Transactions A, vol. 42, pp. 3491-3508, 2011/11/01 2011.

[11] F. A. List, R. R. Dehoff, L. E. Lowe, and W. J. Sames, "Properties of Inconel 625 mesh structures grown by electron beam additive manufacturing," Materials Science and Engineering: $A$, vol. 615, pp. 191-197, 10/6/ 2014.

[12] H. E. Helmer, C. Körner, and R. F. Singer, "Additive manufacturing of nickel-based superalloy Inconel 718 by selective electron beam melting: Processing window and microstructure," Journal of Materials Research, vol. 29, pp. 1987-1996, 2014.

[13] W. J. Sames, F. A. List, S. Pannala, R. R. Dehoff, and S. S. Babu, "The Metallurgy and Processing Science of Metal Additive Manufacturing," International Materials Reviews, 2015 (Invited, Internal Review).

[14] W. J. Sames, K. A. Unocic, R. R. Dehoff, T. Lolla, and S. S. Babu, "Thermal Effects on Microstructural Heterogeneity of Inconel 718 Materials Fabricated by Electron Beam Melting " Journal of Materials Research, vol. 29, pp. 1920-1930, 2014.

[15] K. N. Amato, S. M. Gaytan, L. E. Murr, E. Martinez, P. W. Shindo, J. Hernandez, et al., "Microstructures and mechanical behavior of Inconel 718 fabricated by selective laser melting," Acta Materiala, vol. 60, pp. 2229-2239, 2012.

[16] B. Song, S. Dong, Q. Liu, H. Liao, and C. Coddet, "Vacuum heat treatment of iron parts produced by selective laser melting: Microstructure, residual stress and tensile behavior," Materials \& Design, vol. 54, pp. 727-733, 2// 2014.

[17] S. A. David, S. S. Babu, and J. M. Vitek, "Welding: Solidification and microstructure," JOM, vol. 55, pp. 14-20, 2003/06/01 2003.

[18] S. S. Al-Bermani, M. L. Blackmore, W. Zhang, and I. Todd, "The Origin of Microstructural Diversity, Texture, and Mechanical Properties in Electron Beam Melted Ti-6Al-4V," Metallurgical and Materials Transactions A, vol. 41A, pp. 3422-3434, 2010.

[19] J. Gockel and J. Beuth, "Understanding Ti-6Al-4V Microstructure Control in Additive Manufacturing via Process Maps," in Solid Freeform Fabrication Symposium, Austin, TX, 2013.

[20] L. Thijs, M. L. Montero Sistiaga, R. Wauthle, Q. Xie, J.-P. Kruth, and J. Van Humbeeck, "Strong morphological and crystallographic texture and resulting yield strength anisotropy in selective laser melted tantalum," Acta Materialia, vol. 61, pp. 4657-4668, 7// 2013.

[21] L. P. Parimi, M. M. Attallah, J. C. Gebelin, and R. C. Reed, "Direct Laser Fabrication of Inconel 718," in Superalloys 2012: 12th International Symposium on Superalloys, 2012, pp. 511-519.

[22] R. R. Dehoff, M. M. Kirka, F. A. List, K. A. Unocic, and W. J. Sames, "Crystallographic Texture Engineering Through Novel Melt Strategies via Electron Beam Processing: Inconel 718," Materials Science \& Technology, 2015 (In Press). 
[23] R. R. Dehoff, M. M. Kirka, W. J. Sames, H. Bilheux, A. S. Tremsin, L. E. Lowe, et al., "Site Specific Control of Crystallographic Grain Orientation Through Electron Beam Additive Manufacturing," Materials Science \& Technology, 2015 (In Press).

[24] S. Mitzner, S. Liu, M. Domack, and R. Hafley, "Grain Refinement of Freeform Fabricated Ti-6Al-4V Alloy Using Beam/Arc Modulation," in Solid Freeform Fabrication Symposium, Austin, TX, 2012.

[25] L. Thijs, F. Verhaeghe, T. Craeghs, J. V. Humbeeck, and J.-P. Kruth, "A study of the microstructural evolution during selective laser melting of Ti-6Al-4V," Acta Materialia, vol. 58, pp. 3303-3312, 5// 2010.

[26] D. A. Ramirez, L. E. Murr, E. Martinez, D. H. Hernandez, J. L. Martinez, B. I. Machado, et al., "Novel precipitate-microstructural architecture developed in the fabrication of solid copper components by additive manufacturing using electron beam melting," Acta Materialia, vol. 59, pp. 4088-4099, 6// 2011.

[27] Y. Tian, D. McAllister, H. Colijn, M. Mills, D. Farson, M. Nordin, et al., "Rationalization of Microstructure Heterogeneity in INCONEL 718 Builds Made by the Direct Laser Additive Manufacturing Process," Metallurgical and Materials Transactions A, vol. 45, pp. 4470-4483, 2014/09/01 2014.

[28] "Nickel-Base Superalloys," in Heat Treater's Guide: Practices and Procedures for Nonferrous Alloys, ed: ASM International, 1996, pp. 41-58.

[29] N. Zhou, D. C. Lv, H. L. Zhang, D. McAllister, F. Zhang, M. J. Mills, et al., "Computer simulation of phase transformation and plastic deformation in IN718 superalloy: Microstructural evolution during precipitation," Acta Materialia, vol. 65, pp. 270-286, 2/15/ 2014.

[30] H. F. Merrick, "Effect of heat treatment on the structure and properties of extruded P/M alloy 718," Metallurgical Transactions A, vol. 7, pp. 505-514, 1976/04/01 1976.

[31] I. Kirman and D. H. Warrington, "The precipitation of Ni3Nb phases in a Ni-Fe-Cr-Nb alloy," Metallurgical Transactions, vol. 1, pp. 2667-2675, 1970/10/01 1970.

[32] M. Sundararaman and P. Mukhopadhyay, "Thermal Stability of Deformation Twins in $\gamma^{\prime}-$ Strengthened Alloy 718," Defect and Diffusion Forum, vol. 213-215, pp. 61-74, 2003.

[33] J. F. Radavich, "The Physical Metallurgy of Cast and Wrought Alloy 718," in Superalloy 718 Metallurgy and Applications, TMS, 1989.

[34] R. C. Reed, The Superalloys: Fundamentals and Applications: Cambridge University Press, 2006.

[35] S. Azadian, L.-Y. Wei, and R. Warren, "Delta phase precipitation in Inconel 718," Materials Characterization, vol. 53, pp. 7-16, 9// 2004.

[36] R. G. Thompson, B. Radhakrishnan, and D. E. Mayo, "Intergranular Liquid Formation, Distribution, and Cracking," in Superalloy 718 - Metallurgy and Applications, 1989, pp. 437-455.

[37] L. N. Carter, M. M. Attallah, and R. C. Reed, "Laser Powder Bed Fabrication of Nickel-Base Superalloys: Influence of Parameters; Characterisation, Quantification and Mitigation of Cracking," in Superalloys 2012, ed: John Wiley \& Sons, Inc., 2012, pp. 577-586.

[38] M. Sundararaman and P. Mukhopadhyay, "Overlapping of \$ Igamma"\$ precipitate variants in Inconel 718" Materials Characterization, vol. 31, pp191-196, 1993.

[39] C. Slama, C. Servant, and G. Cizeron, "Aging of the Inconel 718 alloy between 500 and $750{ }^{\circ} \mathrm{C}$," Journal of Materials Research, vol. 12, pp. 2298-2316, 1997. 